\title{
Understanding Online Reading Dispositions from the Perspective of Saudi EFL Learners
}

\author{
https://doi.org/10.3991/ijim.v14i07.11062 \\ Eyhab Talal Yaghi $\left.{ }^{(}\right)$ \\ Majmaah University, Al Majma'ah, Saudi Arabia \\ e.yaghi@mu.edu.sa \\ Amelia Abdullah \\ Universiti Sains of Malaysia, Penang, Malaysia
}

\begin{abstract}
Our knowledge of online reading dispositions is based on limited data. The optimal aim of this paper is to find out the online reading disposition that might take place when EFL students read online materials. To achieve the aim of this research, a mixed method approach was employed. The results emerged from the quantitative data have shown that students tend to show dispositions of reflection as the most frequent dispositions. In compliance with quantitative data, five students were interviewed in order to provide a deep understanding of these dispositions. By doing so, new ideas have been extracted from students' responses such as likeness toward online reading, taking place online reading dispositions and alternatives of online reading dispositions. These emerging results would provide an overwhelming idea about the online reading dispositions and pave the way for upcoming studies.
\end{abstract}

Keywords - Online reading, reading, dispositions and behaviors.

\section{Introduction}

The world today has been witnessing rapid changes in all aspects of our lives. Nowadays people are shifting their thinking and even their way of learning toward technology using and employing diverse applications. Among all these advancements, the internet has turned into the most trusted and reliable source of data where individuals dependably acquire the data they require. Like this, individuals while surfing or paging the internet they demonstrate different dispositions expressing their interest and the way of earning information as well as the way of connecting with others. The reading environment extends from the paper to the digital platform due to progress in technology. With this development, elements like reading comprehension, strategy use, motivation, reading behaviors and attitudes have been questioned [1-3]. As a consequence, online reading dispositions have appeared as a term that explains and characterizes peoples' behaviors while reading on the internet.

The Internet represents a powerful learning tool when used appropriately, but effective use requires multiple skills that are specific to the environment, including searching 
through and accessing information presented in a nonlinear format. Research has shown that while students generally believe they can be successful in an online setting, many do not demonstrate the skills necessary to ensure access to or understanding of content $[4,5]$. As a result, multiple experts have cited the need to expand our knowledge in this area $[6,7]$.

Previous studies endeavored to investigate reading in digital form through analyzing the development that has been taken place in reading or observing how individuals read especially in digital form. Nevertheless, the objective of this study is to explore the students' behaviors in the digital environment and to understand how peoples' behavior changes while reading online. So, understanding the students' dispositions (behavior) might be helpful in outlining more effective and powerful documents on the internet and fostering students' skills in the digital era.

\subsection{Literature review}

Regarding the milestone of literacy, we are currently living in the most rapidly changing phase in the history of literacy. The existence and prevalence of technology and the Internet tempt people to alter their ways of reading. Furthermore, people rely increasingly on the Internet in different aspects of their lives. Therefore, the users of the Internet are close to hitting 3 billion users around the world. In the duration between the years 2000 - 2015, the number of Internet users has dramatically jumped from half a billion users in 2000 to 3 billion users in 2015 .

Currently, Internet has become an inseparable part of people's lives where even the nature of work has changed due to the rising demand on the Internet. Different workplaces, institutions, etc. commenced making fundamental restructuring processes because of the Internet [8-11]. Internet has entered homes in different parts of the world and as a result, access to information has increased. This growth does not mean that people or learners are equipped with necessary skills such as locating, finding and thinking critically about online information $[12,13]$.

Since we are discussing students' reading dispositions in the field of internet; it is mandatory to mention the new literacy theory. This theory resulted in a collaboration of multiple researchers to shape what we call today New literacy Theory.

New literacy theory: Nowadays, we are living in the era of technology where most people around the world become immensely dependable on the internet as a source to find what they want. The number of people using the internet increased sharply in the last decade, and the amount of information found in the space of the internet is enormous. So, these changes that have been taken place rapidly attracted the researchers to investigate the impact of using technology and the internet on people's literacy. As a result, an emerging term appeared to describe these changes; New Literacies is the term that becomes a representation of the literacy state in the 21 st century. The term has been expanded to be a theory $[14,15]$.

"New Literacies" is a controversial issue and becomes an attraction spot for the researchers who give concern to the interfering of technology with education. This term defined as new social practices occur while using new technology and the internet. Currently, some scholars have a belief that new literacies demand to employ new skills, 
strategies and dispositions which are fundamental for online reading comprehension, learning and communication $[15,16]$. On the other hand, some have an encounter belief that it is a merged construct of different orientations [14], while others think that it is a new discourse [17] or new semiotic [18].

The usage of Internet and ICT requires the user to employ new strategies, dispositions and skills. Second, New Literacies provide a space for users to interact, exchange and share interests and information. This new status appeals for the research to explore the benefits of using New Literacies to promote education for all learners around the world. Third, the nature of New Literacies is updated [15]. They are a subject of continuous change. According to San Miguel [19], the change in literacy always concerns with updates in the realm of technology.

As a consequence, users and learners alter their attention from highlighting on reading instructions toward being in touch with the latest updates in New Literacies that will take place during one's lifetime. Fourth, New Literacies take on various forms, models and faces. This feature boosts the complexities of them which is an obstacle to comprehend the new literacies and get benefits from them [20]. In light of this complexity, it is better to undertake research in interdisciplinary teams than follow the traditional investigator model [21].

Online reading comprehension depicted as problem-solving process query that engages different emerging skills, strategies, dispositions and social practices that occur during the usage of internet for different various purposes such as answering questions, solving problems or conducting a research. Leu, Kinzer [15] outlined five leading practices of online reading: 1) reading to identify important questions; 2 ) reading to locate information; 3) reading to evaluate information critically; 4) reading to synthesize information; and 5) reading and writing to communicate information. To be able to perform these tasks effectively, individuals need certain skills and strategies that are special to online reading.

Online reading dispositions: Learning requires capabilities, but capabilities are not enough for learning to take place precisely in academic contexts. Learning should be scaffolded by specific dispositions which according to [22] is a "domain of human attributes not attributed to knowledge, skill, or behavior." Furthermore, Carr and Claxton [23] define disposition as "tendency to edit, select, adapt, and respond to the environment in a recurrent, characteristic kind of way." Basically, a learning disposition is a pattern of behaviors, situated in the context of the environment that when recognized and developed by those who can manipulate the environment, may lead to gains in the acquisition of knowledge, skills, and understandings. Thus, while online reading comprehension involves specific skills and strategies, there exists the likelihood of practical factors that determine how these skills and strategies are used [24].

The current theories of reading comprehension [25] postulate that learning comprises of a number of useful variables [26] and motivational factors [27] that go beyond skills. Furthermore, a body of research $[6,28,29]$ has put in forward a suggestion that these affective variables play an optimal role in reading informational text, and also grow in complexity while engaging in online reading. Therefore, it is foremost to understand the dispositions essential for online reading. So, We define dispositions as the attitudes 
and beliefs, or "habits of the mind" [22] that lead to patterns of behaviors [23], promote gains in the acquisition of knowledge, skills, and understandings [30].

Based on the studies conducted earlier, researchers have extracted five significant dispositions. These dispositions comprise persistence, flexibility, collaboration, reflection and critical stance. Since positive dispositions can guide to effective learning [6, $23,31]$, it was thought that these five dispositions were likely to affect online reading comprehension. The following is a brief explanation of the five dispositions resulted from the previously conducted studies.

- Persistence refers to the firm continuance in a course of action during online reading, despite ongoing difficulties. Online reading is often challenging [5]. It requires rapid, ongoing decision-making, evaluation of those decisions, and frequent revisions to initial decisions about what and where to read as readers locate, evaluate, synthesize and communicate information [6]. Students may give up when they do not find the information they seek.

- Flexibility refers to the learner being able to transfer skills to novel situations and to apply new approaches when the initial approach is unsuccessful. When reading online, students require diverse ways of thinking about conceptual and procedural knowledge [32].

- Collaboration refers to students being able to work together in online environments to problem solve. While offline comprehension has long been operationalized as an individual task, it is becoming evident that learning in the $21^{\text {st }}$ century requires greater collaboration among students.

- Reflection refers to thinking about how you think while continually looking for more effective and efficient ways to expand these abilities. Online reading comprehension requires continual reflection when students monitor and evaluate how they locate, evaluate, synthesize and communicate information [6].

- Finally, Critical stance was defined as having a healthy skepticism on the information that the student is considering. Evaluation of online texts also requires this critical eye [33]. There are many challenges students face when using the Internet because the texts are not vetted, are multimodal, subjected to manipulation, and can be authored by anyone [34].

Carr and Claxton [23] suggest that learning is an interaction of capabilities and dispositions. Studies are emerging that investigate the capabilities of students while reading online, e.g.[4, 35], but little is known of the specific dispositions that strengthen these skills.

Reading on the Internet is appealing to students, yet multiple investigations have revealed that learners often lack knowledge of the different strategies necessary to be successful in online environments. Instead, they employ traditional comprehension strategies, which are necessary, but not sufficient in this context [4, 5]. However, reading is not a skill that we are born with and not a single activity. It is a skill that we learn over time, similar to learning how to speak a different language. It is a complex and variable behavior. It involves different purposes and requires different skills in handling documents. According to the Transaction Theory, a person interacts with reading content like a river connects with its banks; each working each is effects upon the other 
[36]. Therefore, the behavior and the materials have evolved with effect from each other.

McKnight [37] offers a number of excellent insights into the reading behavior of electronic media. He observes that people do not like to read from screens. They prefer to print out electronic documents for reading, even printouts from dot matrix printers. $\mathrm{He}$ argues that the recent trend in mounting electronic documents in Adobe's PDF format also discourages screen reading and encourages printing. People tend to print out documents that are longer than can be displayed on a few screens. People also know how to organize and manipulate paper documents, but manipulating electronic documents requires a different set of skills. People like to browse and find things by accident. Nunberg [38]note:

Browsing a document database will never be quite as informative as browsing a bookstore or library stacks, since electronic documents don't bear physical traces of their provenance the way print books do - the price we pay for delivering them of their bodies. But it may not be much different from browsing around in a video rental outlet.

The importance of dispositions: Positive dispositions — or attitudes, mindsets, and beliefs - are key dimensions of effective learning, particularly for students growing up in a digital information age $[31,39]$. When reading challenging materials offline, a reader's affective states are important. For example, competent readers have a sense of feeling that they are in control of positive or negative outcomes. Moreover, they have a sense of being in control of their learning and being able to self-regulate, knowing what strategies to use in different situations. In addition, skilled offline readers are often characterized as curious, engaged learners who are confident in their abilities to tackle difficult texts. Learners with positive dispositions often seek out challenging reading tasks, and each successful experience reinforces their initiation and use of the comprehension skills and strategies applied. Similarly, as learners' transition into online reading environments, their attitudes and self-efficacy relative to the Internet appear to be important factors that affect motivation and reading performance. Successful online readers are able to manage texts that often change from one day to the next with patience, persistence, and flexibility. In addition, they display creativity and confidence while using the Internet to comprehend diverse online texts.

Tsai and Tsai [40] found that college students with higher Internet self-efficacy used computers more correctly and efficiently, solved problems independently rather than asking for help, and were more apt to criticize and question the information they encountered on the Internet.

In addition to research findings, emerging learning standards demand that online readers must be personally productive, socially responsible, and able to collaborate with other members of a networked global community (Common Core State Standards Initiative, 2010; International Reading Association \& National Council of Teachers of English, 2010). Likewise, $21^{\text {st }}$ century learners are expected to be adaptable, imaginative, self-directed, and emotionally resilient. Having a clearer picture of these expectations can inform the construction of valid assessments to document the development of these affective competencies over time. 


\section{$2 \quad$ Methodology}

\subsection{Population}

The target respondents have been selected randomly from the students of PYP, at Majmaah University. The respondents were studying in the second semester for the academic year 2017/2018. The number of respondents was 170 . The researcher interviewed five students representing the qualitative stage of the study.

\subsection{Research design}

The researcher followed the mixed design method (Quantitative- qualitative). The study is mainly based on the quantitative approach since it suits with the nature of the study and reaches to a large number of respondents. Moreover, to give more deep understanding for the results generated from the quantitative phase, the researcher employed the qualitative approach by interviewing five students who were chosen randomly to state their opinions about motivation to read online.

\subsection{Research instrument}

To achieve the aims of the study, the researcher employed a questionnaire to obtain students responses quantitatively. On the other hand, he conducted interviews with randomly selected students to satisfy the mixed method approach where the researcher mixes between quantitative and qualitative method.

\subsection{Questionnaire}

The researcher utilized [7] questionnaire which employed to measure online reding dispositions. The questionnaire comprises 27 items that cover the five dispositions mentioned earlier. The distribution of the items is as follows: 14 items for reflection, 4 items for critical stance, 3 items for collaboration, 4 items for flexibility, and 2 items for persistence.

In his way to answer the question that focuses on dispositions that occur when students are engaged with online reading, the researcher has adopted this questionnaire with slight changes to suit the students' tertiary level and the aim of the research. The following are the amendments that have been taken place on the questionnaire:

I make a plan before I use the Internet for homework (the original statement).

I make a plan before I use the Internet for assignment (the amended statement).

\subsection{Pilot study}

This section offers information on the results obtained from the pilot study conducted in the context of the study and prior to the main data collection. The latter notion allows for reviewing and correcting data collection tools prior to main data collection [41]. The 
pilot study was conducted among 30 first- year students from the same population, but the sample of the pilot study was excluded from any further data collection.

\subsection{Validity of questionnaire}

In respect to online reading tool validity, the tool has gone through AMOS software to check the validity and reliability of the questionnaire. Results obtained from the pilot study in respect to online reading tool are presented in Table 1 . The results showed that all internal consistency reliability values (ICR) are higher than 0.70 as recommended by Nunnally (1994), ranging from 0.70 to 0.88 . In addition, the AVE results are higher than 0.50 and composite reliability values are higher than the threshold $0.50[42,43]$.

Table 1. Online Reading Disposition Tool Pilot Study Results

\begin{tabular}{|l|c|c|c|}
\hline \multicolumn{1}{|c|}{ Construct } & ICR & AVE & CR \\
\hline Collaboration & 0.76 & 0.58 & 0.80 \\
\hline Critical Stance & 0.91 & 0.84 & 0.95 \\
\hline Flexibility & 0.72 & 0.52 & 0.81 \\
\hline Persistence & 0.90 & 0.82 & 0.90 \\
\hline Reflection & 0.70 & 0.50 & 0.91 \\
\hline
\end{tabular}

In respect to ICR, all constructs exhibit more than 0.70 which is considered above any correlation value among all other constructs. Table 2 exhibits correlations results. The results reveal that all correlation values are between -1 and +1 which according to Hair and Babin [44] values within that range display convergent validity i.e. convergence. Therefore, it can be established that online reading tool is valid to be used for further investigation.

Table 2. Correlation of Online Reading Disposition Constructs

\begin{tabular}{|l|c|c|c|c|c|}
\hline \multicolumn{1}{|c|}{ Constructs } & Collaboration & Critical Stance & Flexibility & Persistence & Reflection \\
\hline Collaboration & 1 & & & & \\
\hline Critical Stance & -0.38 & 1 & & & \\
\hline Flexibility & 0.35 & -0.42 & 1 & & \\
\hline Persistence & 0.49 & -0.43 & 0.72 & 1 & \\
\hline Reflection & 0.33 & -0.59 & 0.61 & 0.74 & 1 \\
\hline
\end{tabular}

\subsection{Reliability of the questionnaire}

This section deals with evidence concerning establishing reliability of the tools used in this research. Specifically, metacognition awareness of reading strategies, motivation, and online reading dispositions tools were undergone reliability analysis. The thresholds recommended by Nunnally, Bernstein [45] and Cortina [46] as shown in Table 3 were employed to evaluate Cronbach's Alpha results from the pilot study in order to judge whether the tools used deemed acceptable reliability scores. 
Table 3. Cronbach's Alpha Thresholds

\begin{tabular}{|c|l|}
\hline Cronbach's Alpha & \multicolumn{1}{|c|}{ Internal Consistency } \\
\hline$\alpha \geq 0.9$ & Excellent \\
\hline $0.7 \leq \alpha<0.9$ & Good \\
\hline $0.6 \leq \alpha<0.7$ & Acceptable \\
\hline $0.5 \leq \alpha<0.6$ & Poor \\
\hline$\alpha<0.5$ & Unacceptable \\
\hline
\end{tabular}

In order to establish reliability in online reading disposition tool, Cronbach Alpha test was used in which it is considered internal consistency most popular test [41]. The results obtained from the pilot study yielded a lowest score i.e. $\alpha=0.68$ and highest score $\alpha=0.93$. Table 4 provides information on scores obtained from the pilot study. According to the Table provided earlier i.e. Table 3 the results range between acceptable and excellent reliability scores.

To sum, the pilot study conducted among university students to assess their online reading disposition revealed that the tool employed in the current work is reliable and valid for further data collection.

Table 4. Cronbach's Alpha results Online Reading Disposition Tool

\begin{tabular}{|l|c|}
\hline \multicolumn{1}{|c|}{ Construct } & Cronbach's Alpha \\
\hline Collaboration & 0.68 \\
\hline Critical Stance & 0.93 \\
\hline Flexibility & 0.69 \\
\hline Persistence & 0.79 \\
\hline Reflection & 0.89 \\
\hline
\end{tabular}

\section{$3 \quad$ Results}

The researcher has conducted the analysis process of students' responses toward the questionnaire distributed for the intended research. However, the results are presented in the following table.

Table 5. The mean and standard deviation of ORDS

\begin{tabular}{|l|c|c|c|}
\hline \multicolumn{1}{|c|}{ Reflection } & Category & Mean & $\begin{array}{c}\text { Standard } \\
\text { Deviation }\end{array}$ \\
\hline $\begin{array}{l}\text { When one strategy does not work to find information on the Internet, I } \\
\text { pick another and keep trying. }\end{array}$ & RT1 & 3.159 & 1.285 \\
\hline I am always learning new things when using the Internet. & RT2 & 3.046 & 1.430 \\
\hline $\begin{array}{l}\text { When I get stuck looking for something online, I am willing to try new } \\
\text { things. }\end{array}$ & RT3 & 3.076 & 1.319 \\
\hline I try hard when using the Internet to learn new things. & RT4 & 3.040 & 1.402 \\
\hline I am ready to learn new things on the Internet even when they are hard & RT5 & 3.036 & 1.370 \\
\hline When searching online gets tough, I am willing to spend extra time. & RT6 & 2.781 & 1.388 \\
\hline I think about the words I choose when I write an email or comment. & RT7 & 3.017 & 1.438 \\
\hline It is important to keep your goal in mind when reading online. & RT8 & 3.185 & 1.369 \\
\hline
\end{tabular}




\begin{tabular}{|c|c|c|c|}
\hline I think about how I am reading when I visit websites. & RT9 & 3.070 & 1.388 \\
\hline I think about my opinion of a subject when reading websites. & RT10 & 3.129 & 1.398 \\
\hline When I choose a website to read, I think back to what I already know. & RT11 & 2.993 & 1.376 \\
\hline I think about what I am doing as I use the Internet. & RT12 & 3.156 & 1.314 \\
\hline I make a plan before I use the Internet for assignments. & RT13 & 3.123 & 1.345 \\
\hline \multirow[t]{2}{*}{ I ask myself if I am finding what I am looking for on the Internet. } & RT14 & 3.103 & 1.366 \\
\hline & & 3.0652 & 1.37057 \\
\hline \multicolumn{4}{|l|}{ Critical Instance } \\
\hline I trust the opinions I read on websites. & CS1 & 2.974 & 1.349 \\
\hline Authors tell the truth when writing on the Internet. & $\mathrm{CS} 2$ & 2.884 & 1.351 \\
\hline I trust what I read on the Internet. & $\mathrm{CS} 3$ & 2.960 & 1.376 \\
\hline \multirow[t]{2}{*}{ You can trust the pictures on websites. } & CS4 & 2.755 & 1.359 \\
\hline & & 2.89 & 1.35 \\
\hline \multicolumn{4}{|l|}{\begin{tabular}{|c|} 
Collaboration \\
\end{tabular}} \\
\hline I enjoy working with classmates when using the Internet. & $\mathrm{CO} 1$ & 2.87 & 1.382 \\
\hline I like doing projects with other people when using the Internet. & $\mathrm{CO} 2$ & 2.81 & 1.377 \\
\hline \multirow[t]{2}{*}{ I can work with a partner to solve problems online. } & $\mathrm{COS}$ & 2.94 & 1.342 \\
\hline & & 2.87 & 1.367 \\
\hline \multicolumn{4}{|l|}{ Flexibility } \\
\hline $\begin{array}{l}\text { Solving problems using the Internet often takes strategies I learned } \\
\text { somewhere else. }\end{array}$ & FL1 & 2.84 & 1.348 \\
\hline Using the Internet requires me to make quick changes in how I read. & FL2 & 2.79 & 1.349 \\
\hline $\begin{array}{l}\text { When searching online, I often have to change the strategies I have used } \\
\text { in the past. }\end{array}$ & FL3 & 2.78 & 1.334 \\
\hline \multirow{2}{*}{$\begin{array}{l}\text { When reading the Internet, you have to look at information by moving } \\
\text { between different viewpoints }\end{array}$} & FL4 & 2.83 & 1.379 \\
\hline & & 2.80 & 1.354 \\
\hline \multicolumn{4}{|l|}{\begin{tabular}{|l|} 
Persistence \\
\end{tabular}} \\
\hline I keep trying when I cannot find what I am looking for on the Internet. & PE1 & 2.92 & 1.362 \\
\hline \multirow[t]{2}{*}{$\begin{array}{l}\text { When I make a mistake when using the Internet, I keep trying until I get } \\
\text { it right. }\end{array}$} & PE2 & 3.02 & 1.388 \\
\hline & & 2.97 & 1.375 \\
\hline
\end{tabular}

The table above demonstrates the responses of the 302 surveyed students for the online reading dispositions they show while online reading. The most frequently occurred dispositions are dispositions that belong to reflection with a mean $(\mathrm{M}=\mathbf{3 . 0 6 5 2 9})$. While the lowest frequently appeared, dispositions are those located under flexibility category with a mean $(\mathrm{M}=2.801)$. The means of the individual items ranged from a high of $(\mathrm{M}=3.185)$ to a low of $(\mathrm{M}=2.775)$. The most frequently reported item was It is important to keep your goal in mind when reading online while the least frequently item was You can trust the pictures on websites.

Based on the table above, students' responses give a reflection about the frequent disposition's students show while online reading. Dispositions that relevant to Reflection scored the highest mean (3.065) and dispositions of Persistence came in the second place (2.970) while the dispositions of flexibility scored the lowest mean (2.801). On the other hand, table 6 discusses the most and least occurring dispositions. 
Table 6. The most and less occurring ORDS

\begin{tabular}{|c|l|c|l|}
\hline \multicolumn{1}{|c|}{ Category } & \multicolumn{1}{|c|}{ Disposition } & \multicolumn{1}{c|}{ Dategory } & \multicolumn{1}{|c|}{ Dess occurring } \\
\hline \multicolumn{1}{|c|}{ Mosition } \\
\hline RT8 & $\begin{array}{l}\text { It is important to keep your goal in mind when } \\
\text { reading online. }\end{array}$ & CO2 & $\begin{array}{l}\text { I like doing projects with other people } \\
\text { when using the Internet. }\end{array}$ \\
\hline RT1 & $\begin{array}{l}\text { When one strategy does not work to find } \\
\text { information on the Internet, I pick another and } \\
\text { keep trying. }\end{array}$ & FL2 & $\begin{array}{l}\text { Using the Internet requires me to make } \\
\text { quick changes in how I read. }\end{array}$ \\
\hline RT12 & $\begin{array}{l}\text { I think about what I am doing as I use the } \\
\text { Internet. }\end{array}$ & RT6 & $\begin{array}{l}\text { When searching online gets tough, I am } \\
\text { willing to spend extra time. }\end{array}$ \\
\hline RT10 & $\begin{array}{l}\text { I think about my opinion of a subject when } \\
\text { reading websites. }\end{array}$ & FL3 & $\begin{array}{l}\text { When searching online, I often have to } \\
\text { change the strategies I have used in the } \\
\text { past. }\end{array}$ \\
\hline RT13 & $\begin{array}{l}\text { I make a plan before I use the Internet for } \\
\text { assignments. }\end{array}$ & CS4 & You can trust the pictures on websites. \\
\hline
\end{tabular}

Regarding the table above, the most occurring dispositions belong to reflection dispositions $100 \%$. On the other hand, the less occurring dispositions were varying between flexibility with $40 \%$ and other disposition were distributed between critical stance, reflection and collaboration with an equal percentage for each one $20 \%$.

In order to investigate more about online reading dispositions, the researcher has undertaken interviews with five students asking them about the foreseen disposition they might expose while online reading. Accordingly, five students were selected randomly and presented to the interviews. Their responses have been recorded and noted verbatim. Table 7 reflects the main themes and subthemes resulted from students' interviews.

Table 7. Codes and categories resulted from Qualitative analysis

\begin{tabular}{|c|l|l|}
\hline No & \multicolumn{1}{|c|}{ Codes } & \multicolumn{1}{c|}{ Categories } \\
\hline 1 & Likeness toward online reading & $\begin{array}{l}\text { Dislike online reading } \\
\text { The amount of reading online } \\
\text { Preferring online reading }\end{array}$ \\
\hline 2 & Taking place Online reading dispositions & $\begin{array}{l}\text { Flexible } \\
\text { Collaborative } \\
\text { Persistence }\end{array}$ \\
\hline 3 & Alternatives of online reading dispositions & $\begin{array}{l}\text { Searching different websites } \\
\text { Asking for assistance }\end{array}$ \\
\hline 4 & The view of online reading dispositions & $\begin{array}{l}\text { Helpful } \\
\text { Difficult } \\
\text { Need developing }\end{array}$ \\
\hline
\end{tabular}

\subsection{Likeness toward online reading}

The data from the participants' interviews indicated that the overwhelming majority of the participants read online, and they have tendency to online reading. For example, AHMAD states "I like online reading and I am reading online to understand international problem such a global warming. Also, ABDULLAH reports his preference to online reading when he says "I read a lot of things online this semester because it 
simplifies the information found in texts or books. I sometimes prefer online texts to reading paper-based texts". Other participant points out that he doesn't keen on reading online and is more interested in short texts than big ones "I don't always read online or on the internet. I also prefer reading short texts to big texts"

In contrast, KHALID expressed his disfavor of online reading and showing his interest of reading books saying "I don't read online, I prefer books. Most likely, I would search for specific information".

\subsection{Taking place online reading dispositions}

In this regard, students' responses were mostly similar. The most frequent dispositions reported by respondents was reflection dispositions. Abdullah says "While online reading, I try to find information in different ways. If one of the sources does not satisfy me, I would go to another source. Therefore, I can move from website to another which becomes more interesting and simpler with different search engines". Faisal depicts himself "I am a flexible person as he reads fast to find the information quickly and fast without wasting time". Beside flexibility, Sultan showed another disposition which reflection is:" The most occurred dispositions I show while online reading are reflection and persistence. It gives me space to learn new things and skills" Ahmad also reported the same "I am fast in reading and show some kind of reflection and flexibility".

\subsection{The view of online reading dispositions}

In response to this points, students' views were different. Khalid point of view of online reading dispositions is that they are helpful is his study: "they are okay with me since they help me in my study". The similarity between Faisal and Sultan is worth mentioning because they revealed that their skills need further development, "I need to develop my online reading skills" and "I need to develop my skills in order to develop my online reading dispositions."

Ahmad's reflection was different since he acknowledged that some of his colleagues face difficulty of employing these dispositions while others consider them easy: "Some students find it difficult and others find it easy, and for me it is not difficult."

\subsection{Alternatives of online reading dispositions}

When the respondents were asked about having alternatives if one of the online reading dispositions fails to achieve the task, they responded with certain ways to overcome this obstacle. Khalid said, "If one of those online reading dispositions fails, I would search in other websites to reach to more specific information. In case that I have not got the satisfied answer, I will ask my friend to help me". On other hand, Abdullah has a different view since he keeps switching between different websites to reach the answer; however, he doesn't ask assistance from his colleagues because he always offers the help, "In the case that one of my dispositions fails or doesn't achieve my purpose of online reading, I will look forward to search in different sources like Youtube or Wikipedia, or switch between different sources to check information. I rarely go to 
books. Personally, I am the one who offers the help and I don't like to receive any help from others."

Faisal and Sultan were approximately similar in their responses to this point. Faisal described himself of being persist and he would read the text again, unless the text was difficult, he will ask for his friend's aid "In case of one of my online reading dispositions fails, I will read the text again and if it is difficult I might ask my friend for assistance. I can chat or WhatsApp him". In the same line, Sultan said, "And if one of these dispositions fails, I will employ persistence such as reading the text again or I might show collaboration by calling and asking my fried to give me an assistance."

On the contrary, Ahmad answer was little bit short and direct. His point of view states "If one of these ORDS fails, I will try different things by reading it again in order to get the main idea." He thinks that repetition of reading the text would be useful and fruitful and might help the reader to grasp the main idea of the text.

\section{Discussion}

Based on the responses of surveyed students, they expose different and varied dispositions. Hence, the findings revealed that the students tend to expose dispositions of flexibility more than other dispositions. In contrast, their lowest frequent dispositions distributed between collaboration, critical stances and reflection dispositions. These findings are some differences from other studies have been conducted in the same field. The following will give insights into the differences between this current study and other researches.

[16] has found that successful online readers have an ability to deal with updates that take place to the texts from one day to day. Also, she mentioned that those skillful online readers show different dispositions while online reading like persistence, flexibility, and patience. Besides, they display creativity and confidence while using the Internet to comprehend various online texts. One study, Tsai \& Tsai found that school students with higher internet self-adequacy utilized PCs more accurately and productively, settled issues autonomously as opposed to requesting help. Also, they were more able to criticize and evaluate the information they experienced on the internet.

One of the most important studies that has addressed this issue directly is [7] created and steered an instrument to inspect online reading dispositions which they depicted as "attitudes and beliefs that lead to the pattern of behavior that promotes the acquisition of the knowledge. The study has discovered three factors, reflection, persistence, and collaboration, were noteworthy in the advancement of online reading dispositions. They called in this study to conduct further research in order to find out more online reading disposition that might take place while students are engaged within online reading. This is inconsistent with the current study where most occurring dispositions are reflection's dispositions.

In contrast to the current study, [47] have conducted a study where they aimed to investigate on the changes in behaviors of online readers. The most striking result in their study was respondents' responses that there was a change in their patience because 
of the large amount of reading material which formed highly pressure over them and negative impact on their patience.

Respondents of the current study revealed their flexibility toward online reading which means that they follow different paths in order to reach what they want. However, the disposition of online reading should be more spotted, and there is a necessity to conduct further research on dispositions and finding the factors that might affect the occurrence of these dispositions.

\section{$5 \quad$ References}

[1] Coiro, J. and E. Dobler, Exploring the online reading comprehension strategies used by sixth-grade skilled readers to search for and locate information on the Internet. Reading research quarterly, 2007. 42(2): p. 214-257. https://doi.org/10.1598/rrq.42.2.2

[2] Lewis, C., New literacies. A new literacies sampler, 2007: p. 229-237.

[3] McKenna, M.C., D.J. Kear, and R.A. Ellsworth, Children's attitudes toward reading: A national survey. Reading research quarterly, 1995: p. 934-956.https://doi.org/10.2307/748205

[4] Coiro, J., Exploring changes to reading comprehension on the Internet. Paradoxes and possibilities for diverse adolescent readers (Thesis doctoral). University of Connecticut, Rhode Island, US, 2007.

[5] Eagleton, T., How to read a poem. 2007: John Wiley \& Sons.

[6] Coiro, J., Rethinking online reading assessment. Educational Leadership, 2009. 66(6): p. 5963.

[7] O'Byrne, W.I. and J.G. McVerry. Measuring the dispositions of online reading comprehension: A preliminary validation study. in National Reading Conference Yearbook. 2009.

[8] Bruce, B.C. Literacy technologies: What stance should we take? 1997. Official Journal of The Literacy Research Association, formerly The National Reading Conference. https:// doi.org/10.1080/10862969709547959

[9] Friedman, T.L., The World Is Flat: A Brief History of the Twenty-First Century (New York: Farrar, Straus and Giroux, 2005). The World Future Society's 'Future Survey"'is an excellent scanning resource, 2005. https://doi.org/10.5465/amp.2006.20591009

[10] Gilster, P. and P. Glister, Digital literacy. 1997: Wiley Computer Pub. New York.

[11] Mikulecky, L. and J.R. Kirkley, Literacy instruction for the 21 st-century workplace. Peabody Journal of Education, 1998. 73(3-4): p. 290-316. https://doi.org/10.1207/s15327930 pje $7303 \& 4 \quad 14$

[12] Cuban, L., H. Kirkpatrick, and C. Peck, High access and low use of technologies in high school classrooms: Explaining an apparent paradox. American educational research journal, 2001. 38(4): p. 813-834. https://doi.org/10.3102/00028312038004813

[13] Madden, A., et al., Using the Internet in teaching: The views of practitioners (A survey of the views of secondary school teachers in Sheffield, UK). British Journal of Educational Technology, 2005. 36(2): p. 255-280. https://doi.org/10.1111/j.1467-8535.2005.00456.x

[14] Lankshear, C. and M. Knobel, New literacies: Everyday practices and classroom learning. 2006: Open University Press.

[15] Leu, D.J., et al., Toward a theory of new literacies emerging from the Internet and other information and communication technologies. Theoretical models and processes of reading, 2004. 5(1): p. 1570-1613. https://doi.org/10.1598/0872075028.54 
[16] Coiro, J., Exploring literacy on the internet: Reading comprehension on the internet: Expanding our understanding of reading comprehension to encompass new literacies. The reading teacher, 2003. 56(5): p. 458-464. https://doi.org/10.1177/1086296x11421979

[17] Gee, J.P., What video games have to teach us about learning and literacy. Computers in Entertainment (CIE), 2003. 1(1): p. 20-20. https://doi.org/10.1145/950566.950595

[18] Kress, G., Literacy in the new media age. 2003: Routledge.

[19] San Miguel, C., Cultural influences on academic literacy: A case study. Open Letter: Australian journal for adult literacy research and practice, 1996. 6(2): p. 31.

[20] Moje, E.B., et al., RRQ Snippet: What will classrooms and schools look like in the new millennium? Reading Research Quarterly, 2000. 35(1): p. 128-134. https://doi.org/10. 1598/rrq.35.1.9

[21] Coiro, J., et al., Handbook of research on new literacies. 2014: Routledge.

[22] Katz, L., The Disposition to Learn. Principal, 1988. 67(5): p. 14-17.

[23] Carr, M. and G. Claxton, Tracking the development of learning dispositions. Assessment in Education: Principles, Policy \& Practice, 2002. 9(1): p. 9-37. https://doi.org/10.1080/ $\underline{09695940220119148}$

[24] Ashford, J.B. and C. LeCroy, Human behavior in the social environment: A multidimensional perspective. 2009: Nelson Education.

[25] Hidi, S., Interest, reading, and learning: Theoretical and practical considerations. Educational psychology review, 2001. 13(3): p. 191-209.

[26] Baker, L. and A. Wigfield, Dimensions of children's motivation for reading and their relations to reading activity and reading achievement. Reading research quarterly, 1999. 34(4): p. 452-477. https://doi.org/10.1598/rrq.34.4.4

[27] Zimmerman, C.B., Self-selected reading and interactive vocabulary instruction: Knowledge and perceptions of word learning among L2 learners. 1994, University of Southern California.

[28] Liaw, M.L., Reading strategy awareness training to empower online reading. The English Teacher, 2017: p. 18.

[29] Raney, A., et al., Regulated translation termination at the upstream open reading frame in Sadenosylmethionine decarboxylase mRNA. Journal of Biological Chemistry, 2002. 277(8): p. 5988-5994. https://doi.org/10.1074/jbc.m108375200

[30] Ennis, R.H., A taxonomy of critical thinking dispositions and abilities. 1987.

[31] Guthrie, J.T., A. Wigfield, and K.C. Perencevich, Scaffolding for motivation and engagement in reading. Motivating reading comprehension: Concept-oriented reading instruction, 2004: p. 55-86. https://doi.org/10.4324/9781410610126

[32] Lawless, K.A. and P. Schrader, where do we go now? Understanding research on navigation in complex digital environments. Handbook of research on new literacies, 2008: p. 267-296.

[33] Fitzgerald, M.A., Critical thinking 101: The basics of evaluating information. Knowledge Quest, 2000. 29(2): p. 13.

[34] Tate, M. and J. Alexander, Teaching critical evaluation skills for World Wide Web resources. Computers in libraries, 1996. 16(10).

[35] Castek, J., et al., Research on instruction and assessment in the new literacies of online research and comprehension. Comprehension instruction: Research-based best practices, 2015: p. 324-344.

[36] Rosenblatt, L.M., The transactional theory of reading and writing. 1994.

[37] McKnight, C. Electronic journals: what do users think of them. in Proceedings of international symposium on research, development and practice in digital libraries. 1997.

[38] Nunberg, G., The advent of the internet. 2012, Courses. 
[39] Popham, W.J., Assessment literacy for teachers: Faddish or fundamental? Theory into practice, 2009. 48(1): p. 4-11. https://doi.org/10.1080/00405840802577536

[40] Tsai, M.-J. and C.-C. Tsai, Information searching strategies in web-based science learning: The role of Internet self-efficacy. Innovations in education and Teaching International, 2003. 40(1): p. 43-50. https://doi.org/10.1080/1355800032000038822

[41] Field, A., Discovering statistics using SPSS. 2009: Sage publications.

[42] Chin, W.W., Commentary: Issues and opinion on structural equation modeling. 1998, JSTOR.

[43] Shepherd, M.M., D.B. Tesch, and J.S. Hsu, Environmental traits that support a learning organization: The impact on information system development projects. Comparative Technology Transfer and Society, 2006. 4(2): p. 196-218. https://doi.org/10.1353/ctt.2006.0022

[44] Hair, J. and W. Babin, B J., Anderson RE (2009) Multivariate data analysis. 2002, NJ: Prentice Hall, Upper Saddle River.

[45] Nunnally, J.C., I.H. Bernstein, and J.M.t. Berge, Psychometric theory. Vol. 226. 1967: McGraw-Hill New York.

[46] Cortina, J.M., What is coefficient alpha? An examination of theory and applications. Journal of applied psychology, 1993. 78(1): p. 98.

[47] Hooper, V. and C. Herath. Is Google Making Us Stupid? The Impact of the Internet on Reading Behaviour. in Bled eConference. 2014

\section{Authors}

Eyhab Talal Yaghi, The Common First Year, English Department, Majmaah University, Al Majma'ah, Saudi Arabia. e.yaghi@mu.edu.sa

Dr. Amelia Abdullah, Program Chairperson for B.Ed (TESOL), School of Educational Studies, Universiti Sains of Malaysia. amelia@usm.my

Article submitted 2019-06-19. Resubmitted 2019-12-29. Final acceptance 2020-01-10. Final version published as submitted by the authors. 